\title{
Exploring the Potential of Natural Products From Mangrove Rhizosphere Bacteria as Biopesticides Against Plant Diseases
}

\author{
Lingyun Hao, ${ }^{1,2}$ Yu Wang, ${ }^{2}$ Xinqi Chen, ${ }^{2}$ Xiaoli Zheng,,${ }^{1,2}$ Si Chen, ${ }^{2}$ Shuangfei Li, ${ }^{2}$ Yu Zhang, ${ }^{2}$ and Ying Xu ${ }^{1,2, \dagger}$ \\ ${ }^{1}$ Guangdong Provincial Key Laboratory for Plant Epigenetics, College of Life Sciences and Oceanography, Shenzhen University, \\ Shenzhen 518060, P.R. China \\ ${ }^{2}$ Shenzhen Key Laboratory of Marine Bioresource \& Eco-environmental Science, Shenzhen Engineering Laboratory for Marine \\ Algal Biotechnology, College of Life Sciences and Oceanography, Shenzhen University, Shenzhen 518060, PR China
}

\begin{abstract}
With increasing concerns of the environmental problems associated with current fungicide application, investigation of alternative, environmentally compatible biopesticides for plant disease management is needed. A total of 113 strains associated with Acanthus ilicifolius Linn in the Maipo Reserve, Hong Kong, were isolated and identified. In vitro assay with crude extracts of bacterial fermentation cultures identified $\sim 26 \%$ of the isolates producing antimicrobial compounds against a variety of agriculturally important phytopathogens. Selected

blast development in pear fruits and rice plants, respectively, when applied at $50 \mu \mathrm{g} \mathrm{ml}^{-1}$. Furthermore, 10 of 14 selected crude extracts with good antimicrobial activities had no significant differences in toxicity to the genus Chlorella compared with the control when used at $25 \mu \mathrm{g} \mathrm{ml}^{-1}$, whereas Amistar Top and Mancozeb completely killed the alga under the same concentration. These data illustrate the potential of natural products from mangrove rhizosphere bacteria in future agricultural application.
\end{abstract} crude extracts with inhibition to Colletotrichum fructicola and Magnaporthe oryzae growth significantly suppressed anthracnose and rice
Keywords: cereals and grains, field crops, fungi, prokaryotes, vegetables
Plant diseases caused by microbial pathogens, especially by fungal pathogens, pose severe threats to agricultural production and have been limiting factors for crop safety and yields for decades (Strange and Scott 2005). Fungicide application remains one of the major disease management strategies for many crops. However, repetitive application of synthetic fungicides not only induces resistance in pathogens but also, causes environmental problems, such as water and soil pollution. In addition, fungicides kill beneficial organisms and may leave chemical residues in produce at poisoning levels to humans (Gullino et al. 2010; Hoppin and LePrevost 2017). The rising public demand for both food security and food safety has stimulated the need to develop alternative environmentally compatible fungicides. These could replace or be applied in combination with traditional fungicides to reduce their application frequency (Rodríguez and Niemeyer 2005). Fewer novel bioactive compounds are being discovered from terrestrial ecosystems, whereas pathogens are more frequently resistant to antimicrobial compounds. Underexplored habitats, such as mangroves, are becoming hot spots for novel drug discovery.

${ }^{\dagger}$ Corresponding author: Y. Xu; boxuying@szu.edu.cn

L. Hao and Y. Wang contributed equally to this work.

Funding: This work was financially supported by Guangdong Innovation Research Team Fund grant 2014ZT05S078, National Natural Science Foundation of China grant 31801788, Research and Development Foundation of Science and Technology of Shenzhen grant JCYJ20180305123932369, and Research Fund for Strategic Emerging and Cultural Industries of Shenzhen grant 201708021308.

*The $\boldsymbol{e}$-Xtra logo stands for "electronic extra" and indicates that one supplementary figure and one supplementary table are published online.

The author(s) declare no conflict of interest.

Accepted for publication 2 May 2019.

C 2019 The American Phytopathological Society
Mangrove communities, distributed in the intertidal zones of tropical and subtropical regions, are mainly composed of woody plants. They feature ecological conditions, such as strong winds, fluctuating redox potential because of tidal variations, and relatively high average temperature with little seasonal change (Thatoi et al. 2013). Owing to their geographical locations, the mangrove wetlands represent a unique ecosystem. They are significantly different from other terrestrial habitats, and they are characterized by high moisture, high salinity, and hypoxia tolerance. Such extreme environmental conditions presumably stimulate unique metabolic adaptations in the associated microbes and thus, enable production of an array of distinct compounds with attractive biological features. According to Ancheeva et al. (2018), the number of research papers describing novel and/or bioactive compounds produced by mangroveassociated microbes almost doubled from 2007 to 2017. This has led to the characterization of almost 1,000 novel metabolites with antifungal, anticancer, antioxidant, and immunosuppressive activities (Ancheeva et al. 2018; Hong et al. 2009; Xu et al. 2014). Furthermore, a number of studies analyzing the microbial communities from mangrove soils have shown a high biodiversity. Many species have been discovered that could not be classified into known genera (de Souza Sebastianes et al. 2013; Liang et al. 2007). This further suggests a potential chemodiversity of natural products from microbes adapted to these specific ecological niches.

Research on bioactive compounds of mangrove/marine origins has mainly focused on medical applications. Studies investigating these natural products in agricultural applications are rare. A few studies have reported that microbes isolated from different marine environments produce antimicrobial compounds against plant pathogens (Chang et al. 2007; Gong et al. 2015; Ortega-Morales et al. 2009; Thatoi et al. 2013). Most of these studies focused on in vitro antagonistic activities between the bioactive compound producers and pathogens but failed to examine their efficacy in planta. Furthermore, few studies have conducted environmental toxicity tests of these compounds in direct comparison with commonly used commercial fungicides (Stefani et al. 2012). For the work reported in this paper, the potential of natural products from mangrove rhizosphere bacteria as environmentally compatible fungicides against plant pathogens was systemically investigated through both in vitro and in planta assays. The hypothesis was that natural products from microbes of this 
habitat may have lower toxicity to environmental organisms than commercial fungicides and thus, the potential to be explored as ecofriendly biopesticides. To investigate this, a library of bacterial isolates associated with a mangrove plant in the Maipo Reserve, Hong Kong was established. These bacteria were screened for antimicrobial compound production against several economically important phytopathogens. The efficacies on pathogen growth inhibition and disease suppression and the aquatic toxicity of crude extracts of bioactive compounds produced by selected isolates were determined and compared with two commercial fungicides. The aim was to provide useful information for future development of novel environmentally compatible biopesticides from mangrove rhizosphere microbes for agricultural application.

\section{Materials and Methods}

Sample collection and bacterial isolation. Soil samples were collected from the rhizosphere of the mangrove plant, Acanthus ilicifolius L., in Maipo Mangrove Nature Reserve, Hong Kong. Samples were then suspended in sterile water at a ratio of $0.01 \mathrm{~g} \mathrm{soil} \mathrm{ml}^{-1}$, and the suspension was evenly spread onto the plates of Marine Agar 2216 (MA; Becton, Dickinson and Company) and modified Difco R2A medium (R2A; Becton, Dickinson and Company) supplemented with $17 \mathrm{~g} \mathrm{liter}^{-1}$ sea salt for bacterial cultivation and isolation. Plates were incubated at $28^{\circ} \mathrm{C}$ for 4 days. Colonies on the plates were observed with a dissecting microscope each day. Morphologically distinct single colonies were selected and subcultured onto the MA and R2A plates, respectively. Pure isolates were then transferred to MA plates and incubated at $28^{\circ} \mathrm{C}$ for 4 days. Then, colonies were suspended into $5 \mathrm{ml}$ of sterile glycerol stock (75\% Marine Broth 2216 and $25 \%$ [vol $/ \mathrm{vol}]$ glycerol) and stored at $-80^{\circ} \mathrm{C}$ in four replicates.

Species identification. Bacterial DNA was extracted with the FASTDNA Spin Kit for Soil (Mpbio) following the manufacturer's instructions. The 16 s ribosomal DNA (rDNA) region was amplified via PCR using the forward and reverse primers, $27 \mathrm{~F}$ and $1492 \mathrm{R}$, as previously described (Lin et al. 2017). The purified PCR product was sequenced at Beijing Genomics Institute. Genus identification was conducted using the blastn program (https://www.ncbi.nlm.nih. gov/BLAST/) based on alignment of the sequencing results with the existing 16s rDNA sequences in the "Nucleotide collection (nr/nt)" database using Megablast. The top-ranked genus with $>97.5 \%$ similarity to the query was selected as the closest relative. Sequences of the 16s rDNA region of all 113 isolates had been deposited to the NCBI database with continuous accession numbers from MK615750 to MK615854 and from MK610666 to MK610673.

Bacterial fermentation. Bacterial isolates were individually streaked onto MA plates. After incubation at $28^{\circ} \mathrm{C}$ for 5 to 7 days, cells of each strain were collected and inoculated into a 50-ml conical tube containing $20 \mathrm{ml}$ of Marine Broth and incubated with shaking $(200 \mathrm{rpm})$ at $28^{\circ} \mathrm{C}$. After 2 to 3 days, cells were grown to the logarithmic stage, and an aliquot $(5 \mu \mathrm{l})$ of the culture from each tube was then transferred into $100 \mathrm{ml}$ of starch, D-(+) glucose, tryptone, yeast extract, peptone, sea salt (SGTYP) broth, which has been used as a fermentation medium to stimulate bioactive compound production (Lin et al. 2017). These cultures were then shaken ( $200 \mathrm{rpm})$ at $28^{\circ} \mathrm{C}$ for 4 days. This timing was chosen, because most strains were found to produce rich profiles of metabolites from the initial analysis by highperformance liquid chromatography. After this fermentation, ethyl acetate (EA; 3:1 original volume) was added into each flask, and metabolites were extracted as previously described (Lin et al. 2017). Crude extract from each strain was weighed, dissolved with dimethyl sulfoxide (DMSO) to a final concentration of $25 \mathrm{mg} \mathrm{ml}^{-1}$, and stored at $4{ }^{\circ} \mathrm{C}$.

In vitro antifungal activity screening. Plant pathogenic fungi causing tomato early blight (Alternaria solani; HLJ65) and corn southern leaf blight (Cochliobolus heterostrophus; Ch16) generously provided by Dr. Zonghua Wang at Fujian Minjiang College (Fuzhou, China) as well as the pathogens causing rice blast (Magnaporthe ory$z a e$; P131) and anthracnose (Colletotrichum fructicola; Cf1) generously provided by Dr. Youliang Peng and Dr. Guozhen Zhang, respectively, at China Agricultural University (Beijing, China) were maintained on Potato Dextrose Agar (PDA; Dickinson and Company) plates under $28^{\circ} \mathrm{C}$.

For the initial screening of crude extracts with antifungal bioactivities, an agar plug was obtained from the edge of a 4-day-old fungal colony of each fungal pathogen with a sterilized glass tube $(6 \mathrm{~mm}$ in diameter). Plugs were placed upside down onto the center of a PDA plate. PDA plates were supplemented with $25 \mu \mathrm{g} \mathrm{ml}^{-1}$ crude extract. PDA plates supplemented with DMSO of the same volume $(0.1 \%)$ were used as negative controls. Two replicates were included per treatment. All plates were sealed with Parafilm and incubated at $28^{\circ} \mathrm{C}$. After 3 days, colony growth in treatments was compared with DMSO-only controls.

Crude extracts with obvious antifungal activities from the initial screening results were further studied, and their inhibitory efficacy at $25 \mu \mathrm{g} \mathrm{ml}^{-1}$ was quantified using the same procedure as described above. Plates supplemented with DMSO were used as negative controls. The diameter of the fungal colony on each plate was measured in two perpendicular directions to each other, and an average value was recorded. Inhibition percentage of each treatment was calculated as $\%$ inhibition $=100 \% \times($ diameter of control - diameter of treatment $) /$ (diameter of control) (Hao et al. 2019). Each treatment included four replicates, and the experiment was repeated at least three times.

In microbes, the genus Streptomyces is known as the most productive genera of bioactive compounds, which are usually extracted by organic solvents, such as EA (Xu et al. 2014). However, certain compounds, such as polysaccharides and peptides, are water soluble and can only be extracted by highly polar-phase solvent. EA treatment would result in disruption of these compounds and thus, loss in bioactivities. To search for novel bioactive compounds that could not be extracted EA, the antifungal activities of the fermentation supernatants of 22 bacterial cultures, identified as genera other than the genus Streptomyces, were also tested using the Oxford plate method $(\mathrm{Xu}$ et al. 2015). Briefly, a fungal mycelium plug obtained from the edge of a 4-day-old colony was placed to the center of the PDA plate, and four sterile paper discs were placed equidistant from each other $\sim 2 \mathrm{~cm}$ from the agar plug. Filter-sterilized supernatant $(10 \mu \mathrm{l})$ from each $20 \mathrm{ml}$ 4-day-old fermentation culture was added to each disc. One disc with $10 \mu$ l of SGTYP broth was included as the negative control, and one control was included per plate. The plates were sealed with Parafilm and incubated at $28^{\circ} \mathrm{C}$ for 4 days before observation.

In vitro antibacterial activity screening. Two phytopathogenic bacteria, Pseudomonas syringae pv. tomato DC3000 and Pectobacterium carotovorum, were provided by Dr. Junna He at China Agricultural University (Beijing, China). The P. syringae pv. tomato culture was maintained on King's B agar plates at $28^{\circ} \mathrm{C}$ for $24 \mathrm{~h}$. Cells were harvested and suspended with King's B broth to an optical density $\left(\mathrm{OD}_{600}\right)=0.2$. Next, the bacterial suspensions were mixed with warm King's B agar medium at a 1:20 ( $\mathrm{vol} / \mathrm{vol})$ ratio and quickly poured into sterile petri dishes. After the plates had completely solidified, four 6-mm-diameter paper discs (200 sterile Xinhua no. 1) were placed onto each plate, and a $4 \mu$ l crude extract of $25 \mathrm{mg} \mathrm{ml}^{-1}$ was pipetted onto each disc. Those with DMSO only were included as negative controls, and at least one control was included per plate. The plates were sealed with Parafilm and incubated at $28^{\circ} \mathrm{C}$ for $48 \mathrm{~h}$. Methods for evaluation of P. carotovorum were the same as those for $P$. syringae pv. tomato, except that Luria Bertani broth and agar were used, cultures were incubated at $37^{\circ} \mathrm{C}$, and test plates were incubated for $24 \mathrm{~h}$. Appearance of transparent zones of inhibited growth surrounding the paper discs was observed.

After observation of zones of inhibition, crude extracts with obvious antibacterial activities were further tested for their inhibition of pathogenic bacteria using a growth curve assay. Briefly, cells grown overnight in King's B (P. syringae pv. tomato DC3000) and Luria Bertani broth $(P$. carotovorum $)$ were adjusted to $\mathrm{OD}_{600}=0.2$ and then diluted to $1: 100$ and 1:1,000, respectively, with the same medium, and a $200-\mu 1$ aliquot of each cell suspension was added into each well of a 96-well plate. Each well contained crude extract at a final concentration of $100 \mu \mathrm{g} \mathrm{ml}^{-1}$ or DMSO of the same volume $\left(0.4 \%\right.$; negative control). Plates were incubated at $28^{\circ} \mathrm{C}$ for 
P. syringae pv. tomato DC 3000 for $48 \mathrm{~h}$ and $37^{\circ} \mathrm{C}$ for $P$. carotovorum for $36 \mathrm{~h}$, and $\mathrm{OD}_{600}$ readings were taken every $12 \mathrm{~h}$ for $P$. syringae pv. tomato or $8 \mathrm{~h}$ for $P$. carotovorum. Each treatment included four replicates, and each experiment was repeated at least three times.

Pathogenicity assay of $\boldsymbol{C}$. fructicola on pear fruits. Pear fruits were purchased from a local grocery store and surface sterilized with $75 \%$ ethanol and sterile water before the pathogenicity assay. Four equidistant wounds with similar depth $(\sim 10 \mathrm{~mm})$ were made by injecting the pears with a 5-ml disposable medical syringe (Jinlong Medical Plastic Appliance Co. Ltd.). After the wounded areas dried, each hole was filled with $100 \mu \mathrm{l}$ crude extract or Amistar Top (20\% azoxystrobin and $12.5 \%$ difenoconazole; Syngenta, U.S.A.) at $50 \mu \mathrm{g}$ $\mathrm{ml}^{-1}$. The fruits were left in a sterile hood until the wounded areas had dried. A C. fructicola mycelial plug (6 $\mathrm{mm}$ in diameter), obtained from the edge of a 4- to 7-day old fungal colony, was placed upside down into each of the wounded areas. Pears with wounds only and compounds only without fungal inoculations were included as controls. All wounds were covered with cotton pieces and wetted with sterile water, and the pears of the same treatment were placed in a sealed bag with three layers of paper towels soaked with sterile water at the bottom and incubated under room temperature $\left(25^{\circ} \mathrm{C}\right)$. After 48 $\mathrm{h}$, the cotton pieces were carefully removed without moving the mycelial plugs, and pears were incubated for additional 5 days. Each pear was sliced, and the surface area and depth of the diseased region that had developed at the inoculation site were measured. The radius of the surface diseased area was measured $(r)$, and the volume of the infected tissue was calculated by the formula:

$$
V=\left(\frac{1}{2}\right) \times\left(\frac{1}{3} \pi r^{3}\right)
$$

Each treatment included four replicates, and the experiment was repeated at least twice.

Pathogenicity assay of M. oryzae on rice seedlings. Rice cultivar Lijiangheigu was grown in potting mix (Shengsheng Agricultural Co. Ltd.) at $26^{\circ} \mathrm{C}$ with a 16-h photoperiod until the third leaf emerged as previously described (Zhang et al. 2014). Complex fertilizer was applied when necessary (Batian Ecological Engineering Co. Ltd.). M. oryzae was cultured on the Tomato Oat-agar medium (TOA), and conidia production was induced by wounding the mycelium twice as previously described (Peng and Shishiyama 1988). Three days after the second round of wounding, $M$. oryzae conidia were collected from the TOA plates with sterile water and filtered through double layers of autoclaved cheesecloth. The final concentration was adjusted to $5 \times 10^{4}$ conidia $\mathrm{ml}^{-1}$ using a hemocytometer, with $0.025 \%$ (vol/vol) Tween 20 added to make plant inoculum. Each crude extract stock or Amistar Top was homogenized with the conidial suspension to a final concentration of $50 \mu \mathrm{g} \mathrm{ml}^{-1}$. Then, each plant was spray inoculated with a 2-ml aliquot of the mixture using a mist sprayer. Plants inoculated with DMSO or pathogen only were included as negative and positive controls, respectively. After inoculation, plants were incubated in the dark at $28^{\circ} \mathrm{C}$ and $100 \%$ relative humidity for $36 \mathrm{~h}$. Then, they were maintained under the same temperature and humidity regime with a 16-h photoperiod. Ten days postinoculation, symptoms were observed primarily on leaf areas closer to the tip end. Therefore, the half of the leaf areas closer to the tip end from the second to the sixth leaves of each plant were rated. The first leaves of plants were excluded from the rating because of natural senescence. The disease rating was based on a 0 to 7 scale as previously described (Shan et al. 2013) with some modifications, including that half of the leaf areas were rated instead of the whole leaf (Supplementary Fig. S1). Disease index was calculated as:

$$
\begin{aligned}
\Sigma \text { (rice blast rating } & \times \text { no of leaves at that rating }) \\
& \times 100 /(\text { total rice leaves } \times 7)
\end{aligned}
$$

Ten to 12 plants were included in each treatment, and the experiment was repeated three times.

Toxicity of crude extracts to algae. Crude extracts with strong antifungal activities were evaluated for toxicity to the green alga, Chlorella salina, and they were compared with commercial fungicides,
Mancozeb (Kelilong Biochemical Co. Ltd.) and Amistar Top as described previously (Dong et al. 2013). Briefly, Chlorella salina was obtained from the Center for Collections of Marine Algae (Xiamen University). Domestication and amplification of the test algae were conducted in $1 \times \mathrm{f} / 2$ medium (Leading Technologies Co., Ltd.) prepared with $33 \%$ o seawater (Guillard 1975 ) at $22^{\circ} \mathrm{C}$ under a photoperiod of $14: 10 \mathrm{~h}$ (dark:light). Crude extracts and fungicide stocks $\left(25 \mathrm{mg} \mathrm{ml}^{-1}\right.$ ) were individually mixed with $500 \mu \mathrm{l}$ of $1 \times \mathrm{f} / 2$ culture medium at a ratio of 1:500 (vol/vol). Then, each crude extract or fungicide mixture was added to $500 \mu \mathrm{l}$ of Chlorella cell suspension in 24-well plates to achieve a final concentration of $25 \mu \mathrm{g} \mathrm{ml}^{-1}$. The starting Chlorella concentration in each well was 50 cells $\mu 1^{-1}$. Chlorella cultures supplemented with DMSO at the volume $(0.1 \%)$ used in the other treatments were included as negative control. The plates were sealed with Parafilm and incubated at $22^{\circ} \mathrm{C}$ under a photoperiod of 14:10 h (dark:light) for 8 days. The numbers of Chlorella cells of each treatment were determined by flow cytometry (Beckman Coulter Co. Ltd.) following the manufacturer's instructions and standard operation procedures. Four replicates were included in each treatment, and the experiment was repeated at least twice.

Statistical analysis. All statistical analyses were performed using the R statistical programming software (version 3.5.1; R Development Core Team, R Foundation for Statistical Computing; http:// www.R-project.org). For in vitro fungal growth inhibition assays, the average inhibition percentage of each crude extract was compared against the expected value of $\mu$, zero (indicating no suppression), in one-sample $t$ tests. For the bacterial growth curve assay, differences in mean $\mathrm{OD}_{600}$ readings between each crude extract treatment and the control group (DMSO) were analyzed using Students' $t$ test. For plant pathogenicity and algal toxicity assays, differences in mean volumes of necrotic tissues of pears, disease index of rice plants, and algal populations among treatments were analyzed using Tukey's honest significant difference test. Significance was set at a $P<0.05$ for all of the aforementioned tests.

\section{Results}

Bacteria isolated from $A$. ilicifolius rhizosphere soil. A total of 113 isolates were identified from the soil associated with the roots of A. ilicifolius. Isolates were assigned to 13 genera based on their $16 \mathrm{~s}$ rDNA sequences (Fig. 1). The genera Streptomyces and Bacillus were most abundant; together, they represented $\sim 79 \%$ of the sample pool. Three genera Micromonospora, Nocardiopsis, and Microbacterium that are commonly associated with plants, soil, or both were also present in our sample pool (Ara et al. 2013; Arrault et al. 2002; Bennur et al. 2015). Multiple isolates were identified within each genus. Other genera, such as genera Tsukamurella, Rhodococcus, Dietzia, Ochrobactrum, and Erythrobacter, contributed only one isolate.

Bacterial isolates produce bioactive compounds against phytopathogens. Most plant biotic diseases are caused by fungal pathogens (Carris et al. 2012), which usually produce conidia that are responsible for secondary infections and disease spread to distant geographic locations. For this reason, our focus was on screening natural products for bioactivities against four economically important fungal pathogens, A. solani, C. fructicola, M. oryzae, and C. heterostrophus. Growth of at least one of the pathogens was inhibited by crude extracts from fermentation cultures of 20 bacterial isolates, including 14 isolates of the genus Streptomyces, four of the genus $\mathrm{Ba}$ cillus, two of the genus Nocardiopsis, and one of the genus Dietzia (Supplementary Table S1). Among these isolates, 70\% produced antifungal metabolites against at least two tested fungi. Two isolates, L59 and L73, with 16s rDNA that shows $100 \%$ similarity to Streptomyces sp. displayed inhibitory effects to all four pathogens. This suggests the production of at least one broad-spectrum antifungal compound. No isolates were found to only target $A$. solani or C. fructicola. Four isolates showed specific inhibition, with average percentages of inhibition ranging from $\sim 48$ to $83 \%$ against $C$. heterostrophus (Fig. 2). These isolates include those identified as the genera Dietzia (L7) and Bacillus (L35 and M6) and Nocardiopsis 
sp. (L86). Two Streptomyces isolates, L60 and L67, had exclusive inhibitory effects on $M$. oryzae.

The crude extract of isolate L97 (Streptomyces sp.) had the highest percentage of inhibition to A. solani ( $60 \%)$. Six other isolates of the genera Bacillus (L14 and L66) and Streptomyces (L59, L73, L75 and L93) showed similar percentages of inhibition ( $50 \%)$ (Fig. 2). The three isolates with the highest inhibitory efficacy against $M$. oryzae included three Streptomyces (L21, L75, and M29) isolates, all having $>70 \%$ inhibitory percentages on fungal growth. Two isolates, L21 and M29, also inhibited $C$. fructicola and C. heterostrophus by $>60$ and $80 \%$, respectively, but had no activity against $A$. solani. In contrast, L93 had $\sim 50 \%$ inhibition on A. solani but no obvious inhibitory activity against $C$. fructicola.

To more thoroughly investigate the potential of natural products from mangrove soil bacteria against fungal pathogens, we also examined the bioactivities of the filter-sterilized supernatant from fermentation cultures of 22 selected non-Streptomyces isolates. One isolate with a closest match to Bacillus subtilis subsp. subtilis (M6) and one with a closest match to Serraria sp. (L2) showed specific inhibitory effects to $A$. solani and $M$. oryzae, respectively (data not shown) that were not seen with their EA crude extracts, indicating the production of potential high polar compounds that would not be extracted by EA in these bacteria.

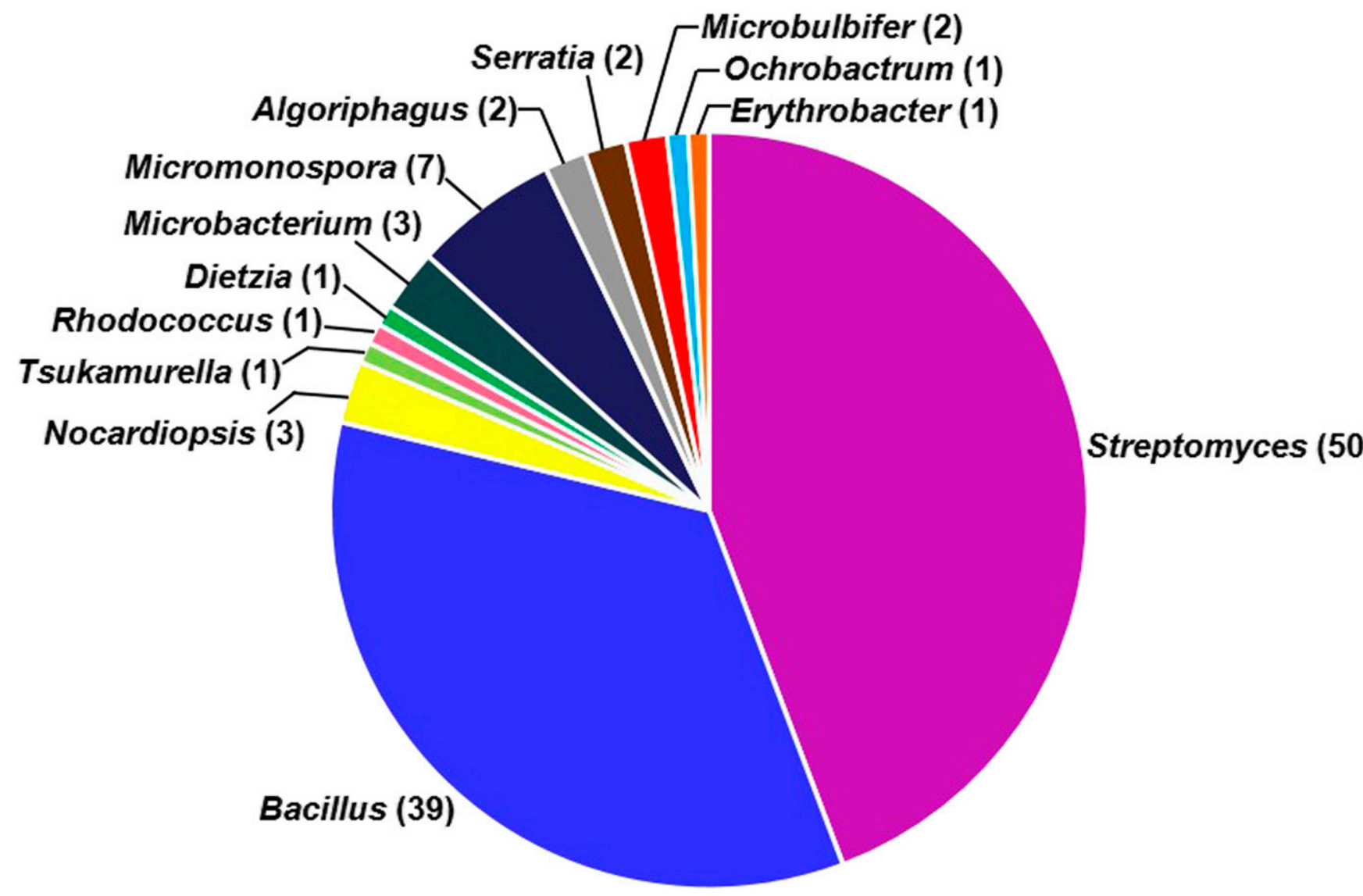

Fig. 1. Classification of bacteria isolated and purified from soil associated with the roots of Acanthus ilicifolius Linn in the Maipo Reserve, Hong Kong. A total of 113 strains were classified based on comparison of 16 s ribosomal DNA sequences with the NCBI database. Numbers of isolates within each genus are shown.

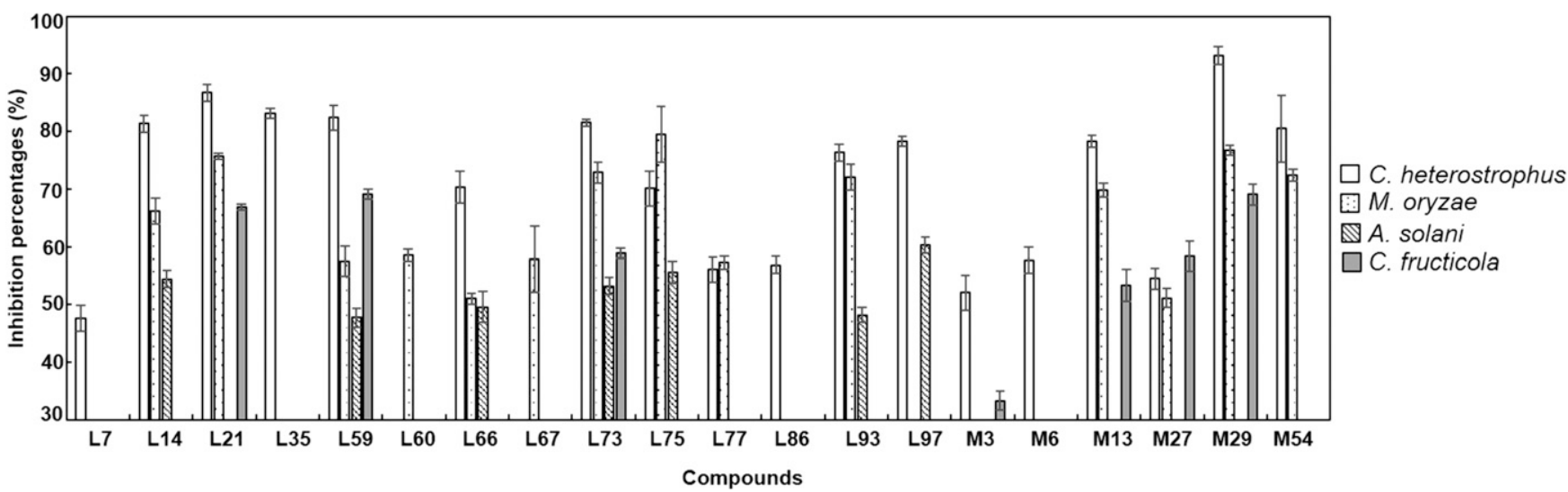

Fig. 2. In vitro inhibition percentages of the crude extracts of selected bacterial fermentation cultures against mycelial growth of Cochliobolus heterostrophus, Magnaporthe oryzae, Alternaria solani, and Colletotrichum fructicola. Crude extracts were supplemented at a final concentration of $25 \mu \mathrm{g} \mathrm{ml}^{-1}$. Mean inhibition percentages were based on 12 replicates per treatment from three independent experiments. Error bars represent standard errors. All of the means are significantly different from zero ( $t$ test, $P<0.001)$, which indicates no suppression on fungal growth. 


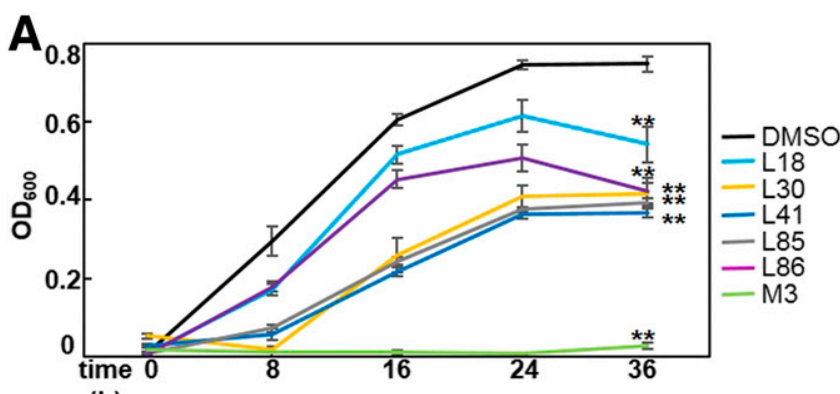

(h)

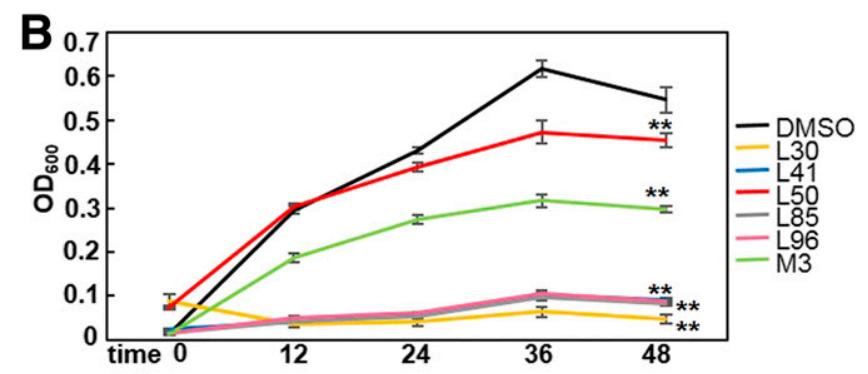

(h)

Fig. 3. Growth of A, Pectobacterium carotovorum and B, Pseudomonas syringae pv. tomato DC3000 treated with crude extracts of selected bacterial fermentation cultures with antibacterial activities. Crude extracts were supplemented at a final concentration of $100 \mu \mathrm{g} \mathrm{ml}^{-1}$, and those supplemented with dimethyl sulfoxide (DMSO, $0.4 \%$ ) were used as negative controls. Average $\mathrm{OD}_{600}$ readings were based on nine replicates per treatment from three independent experiments. Error bars represent standard errors. ${ }^{*}$ Significant difference of $P$ value of $<0.001$ between the mean end point $\mathrm{OD}_{600}$ readings of each treatment and the control (DMSO) using Students' $t$ test.
Crude extracts from fermentation cultures of all 113 isolates were also screened against two phytopathogenic bacteria, $P$. carotovorum and $P$. syringae pv. tomato DC3000. A total of eight isolates produced metabolites with inhibitory effects to at least one of the bacterial pathogens, including two identified as the genus Bacillus (L30 and L41), two identified as the genus Nocardiopsis (L85 and L86), one identified as the genus Algoriphagus (L18), one identified as the genus Streptomyces (M3), one identified as the genus Microbacterium (L50), and one identified as the genus Micromonospora (L96). Although four of the above-mentioned isolates inhibited both P. carotovorum and P. syringae pv. tomato DC3000 (L30, L41, L85, and M3) (Fig. 3), two of them specifically inhibited $P$. syringae pv. tomato DC3000 (L50 and L96), and two specifically inhibited $P$. carotovorum (L18 and L86). Except for M3 and L86, no other isolates showed antimicrobial effects to both fungi and bacteria.

In planta disease suppression efficacy of crude extracts. To confirm the in vitro screening results, we selected five isolates with different inhibitory percentages on $C$. fructicola colony growth, tested their efficacy in disease suppression in pear fruit, and compared activity with that of the commercial fungicide, Amistar Top, whereas fruits inoculated with DMSO served as negative controls. After 7 days of treatment, crude extracts from all five isolates provided observable suppression of anthracnose development on pear fruits (Fig. 4A). Percentages of inhibition ranged from $\sim 33$ to $65 \%$, leading to significantly reduced necrotic regions compared with those of the control (Fig. 4B) $(P<0.05)$, whereas Amistar Top had the highest percentage of inhibition ( 94\%). Crude extracts of L21 and L73 had $\sim 60 \%$ disease suppression, which was comparable with their in vitro inhibitory percentages on fungal growth, whereas those of L59 and L29 had slightly reduced performance when tested in planta compared with the in vitro results. The crude extract of M3 had the lowest percentage of disease suppression in planta, which also showed the lowest percentage of inhibition in vitro.

Crude extracts from four isolates with $>70 \%$ inhibitory percentages to $M$. oryzae growth in vitro were selected and tested for

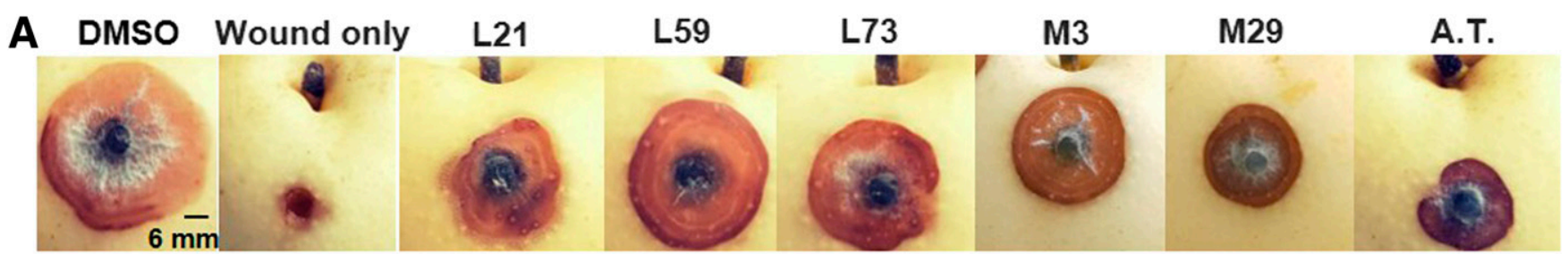

B

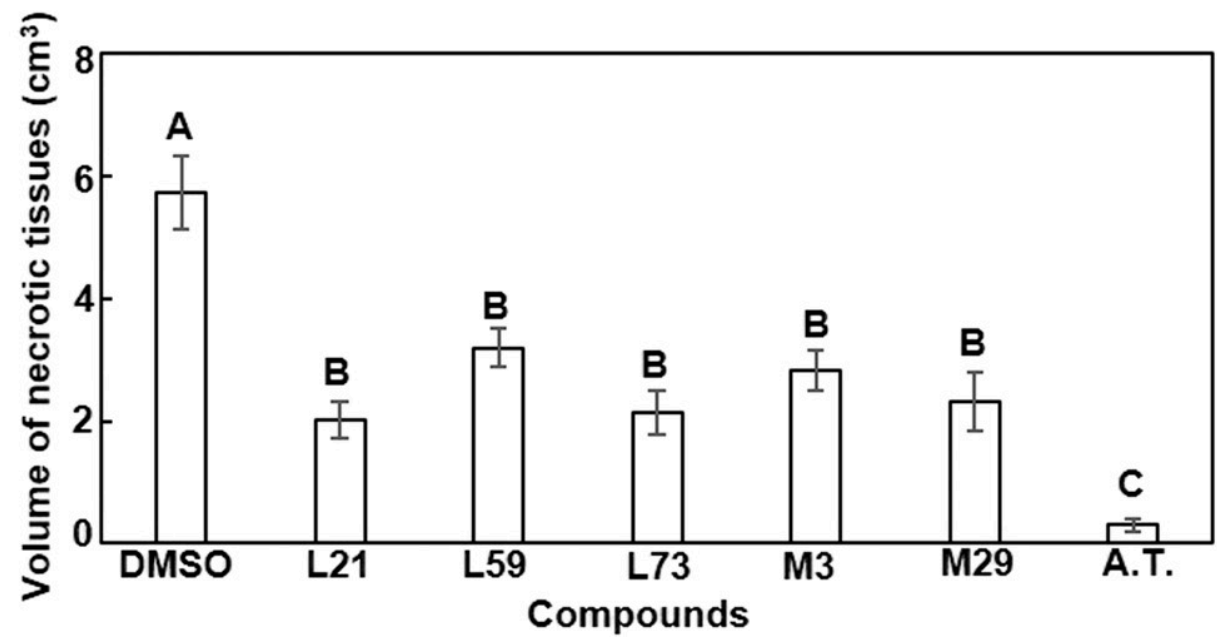

Fig. 4. Anthracnose development on pear fruits treated with crude extracts from selected bacterial fermentation cultures or Amistar Top (A.T.) 7 days postinoculation. A, Representative images of necrotic regions induced by Colletotrichum fructicola on pears, and $B$, mean volumes of necrotic tissues in different treatments. A 100 - $\mu$ l aliquot of each crude extract of $50 \mu \mathrm{g} \mathrm{ml}^{-1}$ was applied to each inoculation site. The averages were based on eight replicates per treatment from two independent experiments. Error bars represent standard errors. Different letters represent significant differences of $P$ values of $<0.05$ between mean volumes of necrotic tissues using Tukey's honest significant difference test. DMSO: Dimethyl sulfoxide. 
suppression of rice blast. After 10 days postinoculation, plants of the control group developed severe symptoms, including large areas of connected necrotic spots with typical blast lesions of elliptical shape, with an average disease index of $\sim 44$ (Fig. 5). In contrast, the necrotic spots in L21-, M29-, and L73-treated plants were much less and confined with little blast lesions developed, with average disease indices of $\sim 34,34$, and 31.5 , respectively, which were all significantly lower than that of the control group $(P<0.01)$. Only the crude extract of isolate L93 did not show obvious disease inhibition effect compared with that of control (average disease index $=39.2, P>0.1$ ). These results supported the in vitro screening approach as a valid first step for effective biopesticide discovery.

Aquatic toxicity of crude extracts. Amistar Top $\left(25 \mu \mathrm{g} \mathrm{ml}^{-1}\right)$ was highly toxic to Chlorella salina and resulted in $100 \%$ mortality of the alga after 8 days of treatment (Fig. 6). Even at $1 \mu \mathrm{g} / \mathrm{ml}$ concentration, Amistar Top caused $\sim 80 \%$ mortality, resulting in significantly smaller algal populations than the control (Fig. 6) $(\mathrm{P}<$ $0.001)$. This result is consistent with its product label, which states that Amistar Top is highly toxic to aquatic organisms ( $\mathrm{Lu}$ et al. 2018). Similar results were found with Mancozeb, which killed all Chlorella salina cells at $\geq 5 \mu \mathrm{g} \mathrm{ml}^{-1}$ and caused $\sim 4 \%$ algal mortality at $1 \mu \mathrm{g} \mathrm{ml}^{-1}$. In contrast, 10 of the 14 tested crude extracts tested at $25 \mu \mathrm{g} \mathrm{ml}^{-1}$ were not significantly different than the control group, which was not toxic. Only three crude extracts caused $>70 \%$

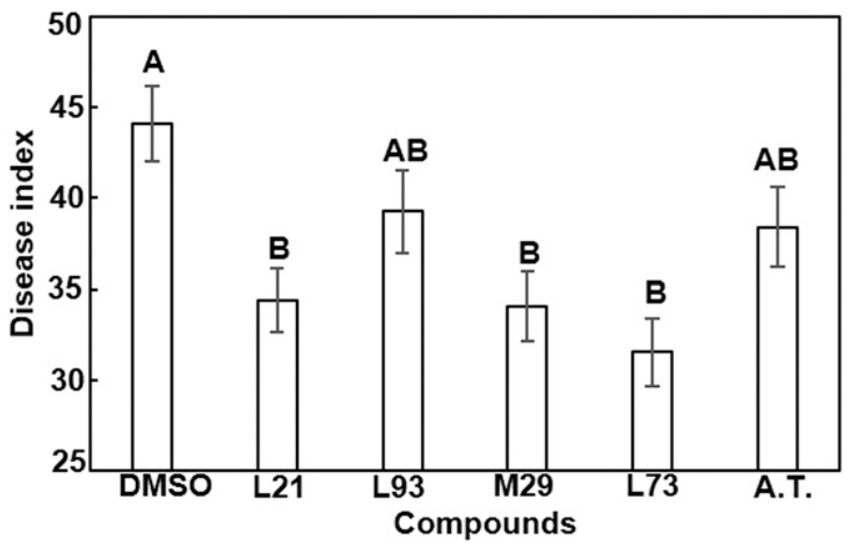

Fig. 5. Inhibition of blast disease development in rice seedlings treated with crude extracts from selected bacterial fermentation cultures or Amistar Top (A.T.). Each plant was spray inoculated with a $2 \mathrm{ml}$ Magnaporthe oryzae conidial suspension of $\sim 1.0 \times 10^{5}$ conidia $\mathrm{ml}^{-1}$ supplemented with dimethyl sulfoxide (DMSO, $0.1 \%$ ) or different crude extracts at a final concentration of $50 \mu \mathrm{g} \mathrm{ml}^{-1}$. Average disease index was calculated based on ratings of 34 to 36 plants per treatment from three independent experiments. Error bars represent standard errors. Different letters represent significant differences of $P$ values of $<0.01$ between mean disease index using Tukey's honest significant difference test. mortality of the alga (L14, M13, and M29). These results suggested that the crude bioactive compound extracts from mangrove soil bacteria generally are less toxic to aquatic organism than the commercial fungicides tested.

\section{Discussion}

With repeated isolation of known natural products from heavily investigated terrestrial microorganisms, underexplored niches, such as desserts, deep oceans, and mangroves, have become likely sources of novel compounds. As one of the most dynamic environments in the world, mangrove soil hosts a large community of bacteria with unique genetic and physiological traits. These bacteria often produce abundant secondary metabolites with various of bioactivities that allow them to survive the changing environment and competition for resources (Jousset et al. 2008). Microbe-derived natural products with antimicrobial features could be superior to the microbes themselves for biological control of plant disease. One reason for this is that the biocontrol organisms may not fit or be competitive enough in the niches where they are applied, and thus, they are not able to reach a population sufficient to produce compounds in the quantities needed for effective disease suppression. In contrast, extracts of the bioactive components can be applied at known concentrations and frequencies, and relatively good consistency and performance can be achieved in disease management. Furthermore, microbe-derived bioactive compounds can be obtained at relatively low cost, which is possible to achieve through optimization of the fermentation process (Tang et al. 2018), and have little alteration to crop horticultural traits.

A. ilicifolius is a native mangrove that is abundant in the Maipo Reserve. This plant is known for producing bioactive compounds with pharmaceutical applications, such as treatment for hepatitis B viral infection (Singh and Aeri 2013). The results of bacterial identification from the rhizosphere of this mangrove plant partially overlap with previous reports that the genera Streptomyces, Bacillus, and Micromonospora are the dominant soil dwellers in the mangrove environment and that bacterial relative abundance varies depending on the geographic location, sampling depth, and the associated plants investigated (Jiang et al. 2013; Ma et al. 2016; Wu et al. 2016). The data from our screening work demonstrate the abundance of bacteria in mangrove soil that may produce antimicrobial compounds with differences in polarity and inhibitory efficacy and specificity that target several fungal and bacterial plant pathogens. More than $25 \%$ of the bacteria produced either antifungal compounds active against at least one of the tested fungi or antibacterial compounds against $P$. syringae pv. tomato DC 3000 or $P$. carotovorum. This demonstrates that these microbes may be a rich reservoir for novel biopesticides exploitation and could be a tool for future disease management.

Actinobacteria are renowned for their biological and genetic diversity, which enables them to produce intriguing secondary metabolites with diversities in both structure and bioactivity (Xu et al. 2014). This is also the case for our screening results, because a majority of the

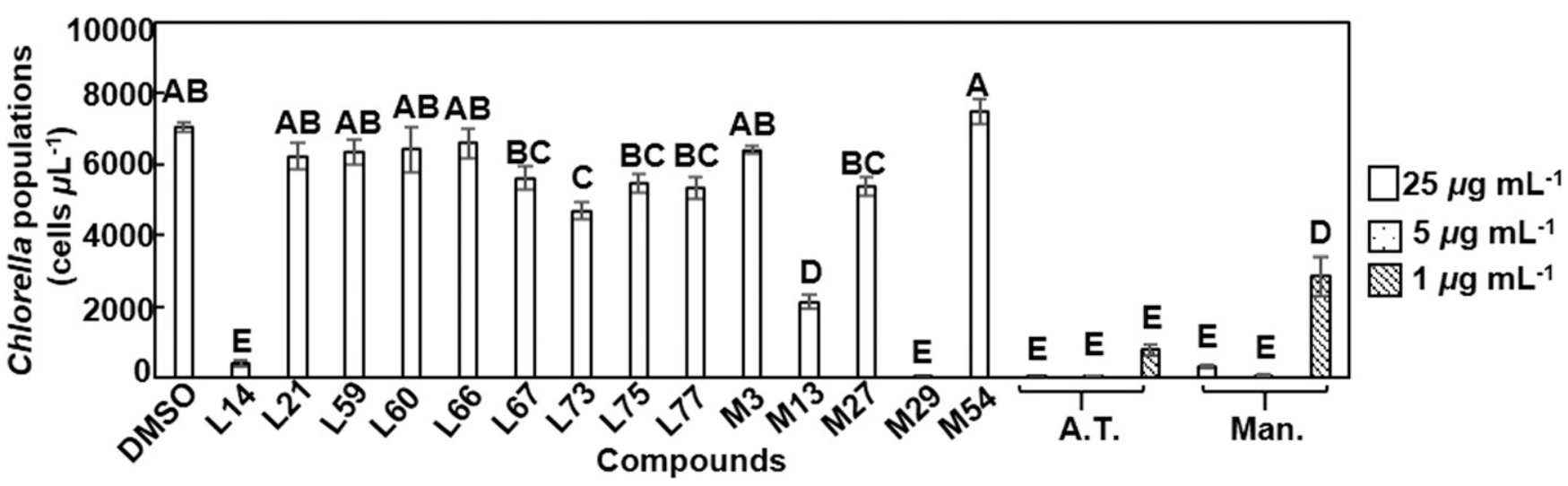

Fig. 6. Toxicity of crude extracts of fermentation cultures from 14 selected isolates or two commercial fungicides Amistar Top (A.T.) and Mancozeb (Man.) to Chlorella salina. Mean $C$. salina populations were based on eight biological replicates per treatment from two independent experiments. Error bars represent standard errors. Different letters represent significant differences of $P$ values of $<0.05$ between mean Chlorella populations using Tukey's honest significant difference test. DMSO: Dimethyl sulfoxide. 
bioactive compounds were produced by Streptomyces and Bacillus isolates. These genera are some of the most studied antimicrobial compound producers (Cumsille et al. 2017; Jackson et al. 2018; Sumi et al. 2015). For example, strains of Streptomyces hydrogenans and Streptomyces cavourensis have been reported to produce diverse antifungal compounds, including cell wall-degrading enzymes, 2furancarboxaldehyde, and bafilomycins, which inhibit plant pathogens, such as Exserohilum sp., Colletotrichum gloeosporioides, Fusarium sp., Rhizoctonia solani, and Botrytis cinerea (Kaur and Manhas 2014; Lee et al. 2012; Pan et al. 2015). The genera Streptomyces and Bacillus have highly conserved 16s rDNA and are difficult to identify to the species level based on DNA alone. Thus, determination of the exact species of the isolates in this study requires additional verification through biochemical and physiological tests (Wang et al. 2018). Moreover, different strains of the same species can produce different compounds or the same compounds with varying yields, resulting in diverse mixtures of bioactive components.

Based on the results of the in vitro bioactivity test, there is a possibility that our isolates produce previously unreported compounds. For example, the crude extract of L97 (Streptomyces sp.) had no activity against $C$. fructicola, whereas the reported strain DH16 of $S$. hydrogenans could inhibit another closely related pathogen, $C$. gloeosporioides (Kaur and Manhas 2014). Because of the differences in fermentation conditions, tested pathogens, and methods used, direct comparison between the two studies is difficult, and compound identification is needed. There is evidence that some of the identified isolates produce novel antimicrobial compounds, such as L7 (Dietzia sp.) and L41 (Bacillus sp.). Additional chemical analysis of the bioactive compounds produced by these isolates using multiple approaches, such as liquid chromatography in conjunction with mass spectroscopy and nuclear magnetic resonance, is currently underway.

The fungal pathogens that we chose to study here represent fungi from different classes that cause devastating diseases to a variety of plants. For example, $A$. solani and $C$. fructicola infect a wide range of economically important vegetable and fruit crops of the Solanaceous and Rosaceous families, respectively (Chaerani and Voorrips 2006). $M$. oryzae and $C$. heterostrophus infect two major staple cereal crops: rice and maize, respectively (Hawes et al. 2016; Talbot 2003). Furthermore, $P$. syringae pv. tomato DC3000 and $P$. carotovorum are two model bacterial pathogens that represent typical colonizers of plant phyllosphere and vascular systems, respectively (Toth et al. 2006; Xin and He 2013). Therefore, isolates producing compounds with antagonistic effects to these economically important pathogens should be further investigated, especially those with bioactivities toward multiple pathogens.

There are certain drawbacks that exist in the approaches of our screening work. For example, we mainly focused on EA extracts of bacterial metabolites, which might miss those bioactive components that are sensitive to EA treatment. This was demonstrated by the bioactivity test results using supernatants from bacterial fermentation cultures. However, the fact that almost $30 \%$ of isolates in our sample pool produced antimicrobial compounds that were extractable by EA proved that our approach is valid as a first step for novel drug discovery in a high-throughput screening system.

Several factors could influence the disease suppression efficacy of crude extracts when applied in planta, such as the ability of chemical diffusion, compound stability, application frequency, and contact between the compound and fungal inoculum. Therefore, it is not surprising that in planta bioefficacy was lower than that of in vitro test results. In both plant assays, crude extracts were applied once at the time of inoculation, and significantly less disease developed compared with the control group at 7 days postinoculation in the pear assay and 10 days postinoculation in the rice plant assay. This suggests relatively good stability of the bioactive compounds. In the field, the dosage, coverage, and timing of pesticide application could have significant impacts on disease management results (Cooke and Little 2001). Therefore, additional investigation on the optimal application timing and frequency as well as the protective and curative effects of these compounds would be necessary before real-world application.
The formulation of bioactive products for commercial application is critical to achieve the most optimal disease management effect, and it is not unusual to have more than one active ingredient in registered fungicides. For example, Amistar Top, a broad-spectrum fungicide widely used for the control of many foliar and fruit diseases (including anthracnose and rice blast), is composed of two active ingredients with two distinct modes of action (product safety sheet; Syngenta). In contrast, crude extracts contain rich profiles of metabolites, and thus, the actual concentrations of the bioactive components might have been $<50 \mu \mathrm{g} \mathrm{ml}^{-1}$. Therefore, it is likely that additional purified compounds could have even better performance in disease suppression in planta. Ongoing identification of the bioactive components of these antimicrobial crude extracts and investigation of whether different components have synergistic or antagonistic effects will provide useful information on the formulation of a potential product for commercialization.

Natural products produced by microbial organisms are generally considered to be ecofriendly, because they have relatively shorter half-life. These compounds are regarded as biodegradable and accumulate less in the environment than synthetic fungicides (Chen et al. 2015). In addition, these products are often active in low dosage, which also reduces the burden introduced into the environment (ElShafei et al. 2010; Saxena and Pandey 2001). Because the pollution caused by pesticide runoff from agricultural land has long been a problem, low toxicity to nontarget organisms is a critical consideration during novel biopesticide development. The genus Chlorella, a common unicellular beneficial green alga, has the characteristics of high photosynthetic efficiency, rapid reproduction, and wide distribution (Yang et al. 2016). In addition, it is a food source for fish, and thus, it plays a critical ecological role in the aquatic system. Therefore, we used this alga to determine the aquatic toxicity of crude extracts with antimicrobial activities in comparison with both fungicides of Mancozeb and Amistar Top. Our data suggest that natural products with good antimicrobial activities generally had far less aquatic toxicity than commercial fungicides, which supports their future application potentials. Additional comprehensive evaluation of the toxicity of these natural products to different environmental organisms as well as examination of their impacts on phytobiomes of the target crops are necessary and will facilitate the development of effective, environmentally compatible biopesticides that can be used in crop protection.

\section{Literature Cited}

Ancheeva, E., Daletos, G., and Proksch, P. 2018. Lead compounds from mangrove-associated microorganisms. Mar. Drugs 16:319.

Ara, I., Bakir, M. A., Hozzein, W. N., and Kudo, T. 2013. Population morphological and chemotaxonomical characterization of diverse rare actinomycetes in the mangrove and medicinal plant rhizosphere. Afr. J. Microbiol. Res. 7:480-488.

Arrault, S., Desaint, S., Catroux, C., Sémon, E., Mougin, C., and Fournier, J. C. 2002. Isolation and characterization of efficient isoxaben-transforming Microbacterium sp strains from four European soils. Pest Manag. Sci. 58: 1229-1235.

Bennur, T., Ravi Kumar, A., Zinjarde, S. S., and Javdekar, V. 2015. Nocardiopsis species: A potential source of bioactive compounds. J. Appl. Microbiol. 120: $1-16$.

Carris, L. M., Little, C. R., and Stiles, C. M. 2012. Introduction to fungi. The Plant Health Instructor. https://doi.org/10.1094/PHI-I-2012-0426-01

Chaerani, R., and Voorrips, R. E. 2006. Tomato early blight (Alternaria solani): The pathogen, genetics, and breeding for resistance. J. Gen. Plant Pathol. 72: 335-347.

Chang, W.-T., Chen, Y.-C., and Jao, C.-L. 2007. Antifungal activity and enhancement of plant growth by Bacillus cereus grown on shellfish chitin wastes. Bioresour. Technol. 98:1224-1230.

Chen, L., Xu, Y., Wang, W., and Qian, P.-Y. 2015. Degradation kinetics of a potent antifouling agent, butenolide, under various environmental conditions. Chemosphere 119:1075-1083.

Cooke, L. R., and Little, G. 2001. The effect of foliar application of phosphonate formulations on the susceptibility of potato tubers to late blight. Pest Manag. Sci. 58:17-25.

Cumsille, A., Undabarrena, A., González, V., Claverías, F., Rojas, C., and Cámara, B. 2017. Biodiversity of Actinobacteria from the South Pacific and the assessment of Streptomyces chemical diversity with metabolic profiling. Mar. Drugs 15:286. 
de Souza Sebastianes, F. L., Romão-Dumaresq, A. S., Lacava, P. T., Harakava, R., Azevedo, J. L., de Melo, I. S., and Pizzirani-Kleiner, A. A. 2013. Species diversity of culturable endophytic fungi from Brazilian mangrove forests. Curr. Genet. 59:153-166.

Dong, F., Li, J., Chankvetadze, B., Cheng, Y., Xu, J., Liu, X., Li, Y., Chen, X., Bertucci, C., Tedesco, D., Zanasi, R., and Zheng, Y. 2013. Chiral triazole fungicide difenoconazole: Absolute stereochemistry, stereoselective bioactivity, aquatic toxicity, and environmental behavior in vegetables and soil. Environ. Sci. Technol. 47:3386-3394.

ElShafei, G. M. S., El-Said, M. M., Attia, H. A. E., and Mohammed, T. G. M. 2010. Environmentally friendly pesticides: Essential oil-based w/o/w multiple emulsions for anti-fungal formulations. Ind. Crops Prod. 31:99-106.

Gong, A.-D., Li, H.-P., Shen, L., Zhang, J.-B., Wu, A.-B., He, W.-J., Yuan, Q.-S., He, J.-D., and Liao, Y.-C. 2015. The Shewanella algae strain YM8 produces volatiles with strong inhibition activity against Aspergillus pathogens and aflatoxins. Front. Microbiol. 6:1091.

Guillard, R. R. 1975. Culture of phytoplankton for feeding marine invertebrates. Pages 29-60 in: Culture of Marine Invertebrate Animals. W. L. Smith and M. H. Chanley, eds. Springer, Boston, MA.

Gullino, M., Tinivella, F., Garibaldi, A., Kemmitt, G., Bacci, L., and Sheppard, B. 2010. Mancozeb: Past, present, and future. Plant Dis. 94:1076-1087.

Hao, L., Zheng, X., Wang, Y., Li, S., Shang, C., and Xu, Y. 2019. Inhibition of tomato early blight disease by culture extracts of a Streptomyces puniceus isolate from mangrove soil. Phytopathology. https://doi.org/10.1094/PHYTO12-18-0444-R

Hawes, M., Allen, C., Turgeon, B. G., Curlango-Rivera, G., Tran, T. M., Huskey, D. A., and Xiong, Z. 2016. Root border cells and their role in plant defense. Annu. Rev. Phytopathol. 54:143-161.

Hong, K., Gao, A.-H., Xie, Q.-Y., Gao, H., Zhuang, L., Lin, H.-P., Yu, H.-P., Li, J., Yao, X.-S., Goodfellow, M., and Ruan, J.-S. 2009. Actinomycetes for marine drug discovery isolated from mangrove soils and plants in China. Mar. Drugs 7:24-44.

Hoppin, J. A., and LePrevost, C. E. 2017. Pesticides and human health. Pages 249-273 in: Environmental Pest Management. M. Coll and E. Wajnberg, eds. Wiley, Hoboken, NJ.

Jackson, S., Crossman, L., Almeida, E., Margassery, L., Kennedy, J., and Dobson, A. 2018. Diverse and abundant secondary metabolism biosynthetic gene clusters in the genomes of marine sponge derived Streptomyces spp. isolates. Mar. Drugs 16:67.

Jiang, X.-T., Peng, X., Deng, G.-H., Sheng, H.-F., Wang, Y., Zhou, H.-W., and Tam, N. F.-Y. 2013. Illumina sequencing of 16S rRNA tag revealed spatial variations of bacterial communities in a mangrove wetland. Microb. Ecol. 66: 96-104.

Jousset, A., Scheu, S., and Bonkowski, M. 2008. Secondary metabolite production facilitates establishment of rhizobacteria by reducing both protozoan predation and the competitive effects of indigenous bacteria. Funct. Ecol. 22:714-719.

Kaur, T., and Manhas, R. K. 2014. Antifungal, insecticidal, and plant growth promoting potential of Streptomyces hydrogenans DH16. J. Basic Microbiol. 54:1175-1185

Lee, S. Y., Tindwa, H., Lee, Y. S., Naing, K. W., Hong, S. H., Nam, Y., and Kim, K. Y. 2012. Biocontrol of anthracnose in pepper using chitinase, beta-1,3 glucanase, and 2-furancarboxaldehyde produced by Streptomyces cavourensis SY224. J. Microbiol. Biotechnol. 22:1359-1366.

Liang, J.-B., Chen, Y.-Q., Lan, C.-Y., Tam, N. F. Y., Zan, Q.-J., and Huang, L.-N. 2007. Recovery of novel bacterial diversity from mangrove sediment. Mar. Biol. 150:739-747.

Lin, H.-N., Wang, K.-L., Wu, Z.-H., Tian, R.-M., Liu, G.-Z., and Xu, Y. 2017. Biological and chemical diversity of bacteria associated with a marine flatworm. Mar. Drugs 15:281.

Lu, T., Zhu, Y., Xu, J., Ke, M., Zhang, M., Tan, C., Fu, Z., and Qian, H. 2018. Evaluation of the toxic response induced by azoxystrobin in the non-target green alga Chlorella pyrenoidosa. Environ. Pollut. 234:379-388.

Ma, Z. P., Lao, Y. M., Jin, H., Lin, G. H., Cai, Z. H., and Zhou, J. 2016. Diverse profiles of AI-1 type quorum sensing molecules in cultivable bacteria from the mangrove (Kandelia obovata) rhizosphere environment. Front. Microbiol. 7: 1957.

Ortega-Morales, B. O., Ortega-Morales , F. N., Lara-Reyna, J., De la Rosa-García, S. C., Martínez-Hernández, A., and Montero-M., J. 2009. Antagonism of Bacillus spp. isolated from marine biofilms against terrestrial phytopathogenic fungi. Mar. Biotechnol. (NY) 11:375-383.

Pan, H. Q., Yu, S. Y., Song, C. F., Wang, N., Hua, H. M., Hu, J. C., and Wang, S. J. 2015. Identification and characterization of the antifungal substances of a novel Streptomyces cavourensis NA4. J. Microbiol. Biotechnol. 25:353-357.

Peng, Y.-L., and Shishiyama, J. 1988. Temporal sequence of cytological events in rice leaves infected with Pyricularia oryzae. Can. J. Bot. 66:730-735.

Rodríguez, L. C., and Niemeyer, H. M. 2005. Integrated pest management, semiochemicals and microbial pest-control agents in Latin American agriculture. Crop Prot. 24:615-623.

Saxena, S., and Pandey, A. K. 2001. Microbial metabolites as eco-friendly agrochemicals for the next millennium. Appl. Microbiol. Biotechnol. 55: 395-403.

Shan, H., Zhao, M., Chen, D., Cheng, J., Li, J., Feng, Z., Ma, Z., and An, D. 2013 Biocontrol of rice blast by the phenaminomethylacetic acid producer of Bacillus methylotrophicus strain BC79. Crop Prot. 44:29-37.

Singh, D., and Aeri, V. 2013. Phytochemical and pharmacological potential of Acanthus ilicifolius. J. Pharm. Bioallied Sci. 5:17-20.

Stefani, A. J., Felício, J. D., and de Andréa, M. M. 2012. Comparative assessment of the effect of synthetic and natural fungicides on soil respiration. Sensors (Basel) 12:3243-3252.

Strange, R. N., and Scott, P. R. 2005. Plant disease: A threat to global food security Annu. Rev. Phytopathol. 43:83-116.

Sumi, C. D., Yang, B. W., Yeo, I.-C., and Hahm, Y. T. 2015. Antimicrobial peptides of the genus Bacillus: A new era for antibiotics. Can. J. Microbiol. 61:93-103.

Talbot, N. J. 2003. On the trail of a cereal killer: Exploring the biology of Magnaporthe grisea. Annu. Rev. Microbiol. 57:177-202.

Tang, B., Sun, C., Zhao, Y., Xu, H., Xu, G., and Liu, F. 2018. Efficient production of heat-stable antifungal factor through integrating statistical optimization with a two-stage temperature control strategy in Lysobacter enzymogenes OH11. BMC Biotechnol. 18:69.

Thatoi, H., Behera, B. C., Mishra, R. R., and Dutta, S. K. 2013. Biodiversity and biotechnological potential of microorganisms from mangrove ecosystems: A review. Ann. Microbiol. 63:1-19.

Toth, I. K., Pritchard, L., and Birch, P. R. J. 2006. Comparative genomics reveals what makes an enterobacterial plant pathogen. Annu. Rev. Phytopathol. 44 305-336.

Wang, K., Song, Z., Rong, C., Hao, L., Lai, Q., Li, S., and Xu, Y. 2018 Kandeliimicrobium roseum gen. nov., sp. nov., a new member of the family Rhodobacteraceae isolated from mangrove rhizospehre soi. Int. J. Syst. Evol. Microbiol. 68:2158-2164.

Wu, P., Xiong, X., Xu, Z., Lu, C., Cheng, H., Lyu, X., Zhang, J., He, W., Deng, W., Lyu, Y., Lou, Q., Hong, Y., and Fang, H. 2016. Bacterial communities in the rhizospheres of three mangrove tree species from Beilun Estuary, China. PLoS One 11:e0164082.

Xin, X. F., and He, S. Y. 2013. Pseudomonas syringae pv. tomato DC3000: A model pathogen for probing disease susceptibility and hormone signaling in plants. Annu. Rev. Phytopathol. 51:473-498.

Xu, D.-B., Ye, W.-W., Han, Y., Deng, Z.-X., and Hong, K. 2014. Natural products from mangrove actinomycetes. Mar. Drugs 12:2590-2613.

Xu, G. B., Pu, X., Bai, H. H., Chen, X. Z., and Li, G. Y. 2015. A new alternariol glucoside from fungus Alternaria alternate cib-137. Nat. Prod. Res. 29: 848-852.

Yang, B., Liu, J., Jiang, Y., and Chen, F. 2016. Chlorella species as hosts for genetic engineering and expression of heterologous proteins: Progress, challenge and perspective. Biotechnol. J. 11:1244-1261.

Zhang, H., Wu, Z., Wang, C., Li, Y., and Xu, J.-R. 2014. Germination and infectivity of microconidia in the rice blast fungus Magnaporthe oryzae. Nat. Commun. 5:4518. 